\title{
Het genereren en evalueren van voorspellingen van omzet en netto winst
}

\section{Inleiding}

Accurate voorspellingen van bedrijfsresultaten, m.n. van omzet en winst, zijn van belang voor een onderneming. Het management wordt erdoor in de gelegenheid gesteld tijdig in te spelen op ongewenste ontwikkelingen van deze resultaten. Makelaars, beleggers, huidige en toekomstige eigenaren van een onderneming zijn erbij gebaat dat zij over nauwkeurige prognoses van de bedrijfsresultaten beschikken. Beleggers streven bij een gegeven risiconiveau naar een maximaal rendement, of bij een bepaald rendement naar een minimaal risico. Voor de belegger, die wil investeren, is het dan ook van belang, dat hij van diverse fondsen informatie heeft over toekomstige opbrengsten en de daarbij behorende risico's. De belegger kan gewenste informatie omtrent dividendbeleid, omzet- en winstprognoses echter op diverse manieren verkrijgen, bijvoorbeeld door de bedrijfsleiding, financiële analisten of beleggingsbladen te raadplegen of door zelf te voorspellen op basis van historische bedrijfsgegevens.

In het buitenland, m.n. in de V.S., is er vergelijkend onderzoek gedaan naar de kwaliteit van prognoses afgegeven door het management, door financiële analisten en door personen, die enkel op basis van gepubliceerd historisch materiaal van een onderneming voorspellen. Voor Nederland heeft het Economisch en Sociaal Instituut (E.S.I.) van de Vrije Universiteit, Amsterdam, een onderzoek opgezet naar de vraag of en in hoeverre beleggers en andere belanghebbenden erbij gebaat zijn dat ondernemingen prospectieve informatie verstrekken, dan wel dat zij bij financiële analisten te rade gaan. Dit impliceert dat de eventueel verstrekte informatie elementen bevat, die niet door de belanghebbende op basis van het historische materiaal afgeleid kunnen worden. In het onderzoek zal ook nagegaan worden welke van de drie groepen, te weten ondernemingen, financiële analisten en tijdreeksanalisten de meest accurate voorspellingen kan genereren; hierbij kan eventueel aangegeven worden onder welke condities deze rangorde van toepassing is.

Daar het in Nederland niet gebruikelijk is, dat er prognostische informatie gepubliceerd wordt, zijn alle ter beurze genoteerde N.V.'s en de leden van de Vereniging van Beleggingsanalisten aangeschreven. Zij werden gevraagd de voorspellingen van omzet en netto winst over het boekjaar 1980 te deponeren bij een notaris. Er is ook gevraagd naar voorspellingsintervallen 
(n.l. $50 \%$ en $100 \%$ ) voor de te voorspellen grootheden. Teneinde oneigenlijk gebruik te voorkomen, is er met de inzenders overeengekomen dat de voorspellingen pas in 1981 zouden worden geëvalueerd. Over het prognoseonderzoek van het E.S.I. zal in een afzonderlijke publicatie gerapporteerd worden.

In dit artikel beperken wij ons tot de methodologische aspecten van het genereren van voorspellingen m.b.v. simpele tijdreeksmodellen. Het onderzoek, waarover hier gerapporteerd wordt, is verricht om in het kader van het prognose-onderzoek van het E.S.I. een leidraad te ontwikkelen voor het genereren van voorspellingen van bedrijfsresultaten m.b.v. modellen. Naar wij hopen zal deze bijdrage ook van belang zijn voor de in 'Planning en Forecasting' geïnteresseerde lezer. Aan de hand van enkele voorbeelden zullen wij proberen aan te geven hoe en in hoeverre modellen gebruikt kunnen worden om omzet en winst van een onderneming te voorspellen. In een kort overzicht van de literatuur zal aangegeven worden, welke eenvoudige voorspelmodellen vaak geselecteerd worden (hoofdstuk 2) en hoe de voorspelkwaliteit van tijdreeksmodellen zich verhoudt tot die van de prognoses van ondernemingen en financiële analisten (hoofdstuk 3). Daarna wordt in hoofdstuk 4 nader ingegaan op de mogelijkheden van en beperkingen bij het toepassen van simpele voorspelmethoden. Hoofdstuk 5 is gewijd aan een aantal voorbeelden, waarbij we proberen aan te geven hoe we tot de keuze van een model komen. We besluiten dit artikel met enkele evaluerende conclusies.

\section{Voorspelmodellen voor winst en omzet}

In de accounting literatuur is reeds veel onderzoek verricht naar het voorspellen van financiële gegevens met behulp van eenvoudige, meestal niet-causale modellen (zie tabel 1), zoals bijv. een stochastische wandeling, trendextrapolatie, identieke verandering - zowel in procenten als absoluut, en de methode van evenredige correctie. Daarnaast wordt steeds vaker voorspeld m.b.v. 'Autoregressive Integrated Moving Average' modellen (zie ook Hopwood en Newbold (1980)). Deze klasse van modellen, die uitvoerig beschreven wordt in Box en Jenkins (1970) en in Nelson (1973), zullen we afkorten als ARIMA modellen. De meest gangbare enkelvoudige tijdreeksmodellen zijn vermeld in de volgende tabel. 
1. constant niveau

2. lineaire trend

3. stochastische wandeling of random walk (met constante)

4. verwachte identieke mutatie

5. ARIMA model (p, d, q)

$$
\begin{aligned}
& \underline{y}_{t}=\delta+\underline{\varepsilon}_{t} \\
& \underline{y}_{t}=\delta+\beta t+\underline{\varepsilon}_{t}
\end{aligned}
$$

$$
\begin{aligned}
& \underline{y}_{t}=y_{t-1}+\underline{\varepsilon}_{t}(+\delta) \\
& y_{t}=y_{t-1}+\left(y_{t-1}-y_{t-2}\right)+\underline{\varepsilon}_{t} \\
& \Delta^{d} y_{t}=\delta+\sum \varnothing_{i} \Delta^{d} y_{t-i}+
\end{aligned}
$$

$\stackrel{4}{\sum} \theta_{i} \varepsilon_{i-i}+\underline{\varepsilon}_{q}$

In tabel 1 is $\underline{y}_{t}$ de te voorspellen variabele; $\underline{\varepsilon}_{t}$ is een normaal verdeelde witte ruis, d.w.z. een storingsterm met gemiddelde nul, variantie $\sigma^{2}$ en autocorrelaties nul. $\Delta$ is de verschil-operator ( $\Delta^{\mathrm{d}}$ : het $\mathrm{d}$-de verschil). Indien wij op tijdstip $\mathrm{t}-1$ de voorwaardelijke verwachting van $\mathrm{y}_{t}, \mathrm{E}\left(\mathrm{y}_{\mathrm{t}} \mid \mathrm{y}_{\mathrm{t}-1}, \mathrm{y}_{\mathrm{t}-2}, \ldots\right)$, gebruiken om één periode vooruit te voorspellen, dan is de voorspelfout gelijk aan $\underline{\varepsilon}_{\mathrm{t}}$. Verder is het eenvoudig na te gaan, dat alle in tabel 1 vermelde modellen behoren tot de klasse van ARIMA modellen (zie hiervoor m.n. Van Winkel (1979)).

In de overwegend Amerikaanse literatuur komt men analyses van voorspellingen op jaar- en kwartaalbasis tegen. De problematiek, die met het laatstgenoemde samenhangt wordt o.a. beschreven in Foster (1977). Omzeten kostenreeksen vertonen veelal een seizoenpatroon, terwijl dit bij winstreeksen veel minder het geval is. Foster (1977) analyseert kwartaalgegevens betreffende omzet, winst en uitgaven voor 69 Amerikaanse bedrijven. Hierbij gebruikt hij eenvoudige voorspellers voor de variabele $y_{t}$, zoals $\mathrm{E}\left(\mathrm{y}_{\mathrm{t}}\right)=\mathrm{y}_{\mathrm{t}-\mathrm{i}}+\delta, \mathrm{i}=1,4$, met een constante $\delta$ en ook zonder constante, of $E\left(y_{t}\right)=y_{t-4}+\varnothing\left(y_{t-1}-y_{t-5}\right)+\delta$ of een Box-Jenkins (BJ)model. Het BJmodel is een univariaat ARIMA model verkregen uit de analyse van de autocorrelaties en partiële autocorrelaties van de reeksen.

Uit het onderzoek van Foster blijkt dat de voorspelkwaliteit van de voorspeller $\mathrm{y}_{\mathrm{t}-4}+\varnothing\left(\mathrm{y}_{\mathrm{t}-1}-\mathrm{y}_{\mathrm{t}-5}\right)+\delta$ beter is dan die van de simpeler modellen en de BJ-modellen. Als mogelijke oorzaak hiervan noemt hij specificatiefouten en kleine steekproef-bias.

Voor voorspellingen op jaarbasis laten Watts en Leftwich (1977) zien, dat - bij gebruikmaking van het criterium minimale relatieve voorspelfout modellen bepaald volgens de BJ-methodiek slechter voorspellen dan het random walk model. De resultaten gevonden door Watts en Leftwich (1977) bevestigen de conclusies van Ball en Watts (1972). Elton en Gruber (1972) 
concluderen dat een additief exponentieel model nauwkeuriger één, twee, en drie jaar vooruit voorspellingen oplevert dan naïeve modellen, zoals een model met een lineaire trend. Ook geldt voor hun resultaten dat met de toename van de voorspellingshorizon ook de voorspelkwaliteit van ingewikkelder modellen ten opzichte van de naïeve modellen toeneemt.

\section{Management en analisten contra modellen}

$\mathrm{Bij}$ het vergelijken van de voorspelkracht van de verschillende groepen veronderstelt men meestal a priori, dat het management het best tot voorspellen in staat is. Hierbij gaat men er vanuit dat de onderneming op de hoogte is van de eigen specifieke ontwikkeling binnen het marktgebeuren (zie Ruland (1978)). In het kwantitatieve empirische onderzoek onderschrijft men bovenstaande veronderstelling echter niet volledig. Green en Segall (1967) concluderen onder meer dat de voorspelkwaliteit van simpele extrapolaties niet veel onderdoet voor voorspellingen van het management. Lorek, McDonald en Patz (1976) vinden zelfs dat voorspellingen gerealiseerd volgens de Box-Jenkins methode beter scoren dan die van het management - althans voor kwartaalgegevens. Dat er veel verdeeldheid in de literatuur bestaat, blijkt o.a. doordat Ruland (1978) en Basi, Carey en Twark (1976) tot de conclusie komen dat het management beter voorspelt dan de financiële analisten, die toch ook naïeve voorspelmethoden kunnen gebruiken. Een ander resultaat van Ruland (1978) is dat zowel management als analisten beter voorspellen dan de eenvoudige tijdreekstechnieken. Elton en Gruber (1972) vinden dat de voorspelkwaliteit van analisten niet significant verschilt van die van eenvoudige tijdreeksmodellen. Uit het onderzoek van Ruland (1978) komt ook naar voren dat financiële analisten slechter voorspellen dan het management, indien zij hun voorspelling doen voor de managementvoorspelling. Voorspellen ze na het management, dan ontloopt de voorspelkwaliteit elkaar niet veel. Financiële analisten zijn mogelijk in staat een gekleurde prognose van het management te vertalen naar een normaal niveau.

Daarnaast komt men de volgende conclusies vaak tegen in de literatuur:

- Voorspellingen van de bedrijfsresultaten voor de dienstensector zijn in het algemeen met grotere nauwkeurigheid te maken, dan die van bedrijven die zich in de industriële sector bewegen.

- De resultaten van ondernemingen die iets ouder zijn en zich niet in een turbulente omgeving bevinden zijn eenvoudiger te voorspellen.

- In jaren dat de conjunctuur omslaat, of dat de winst gemiddeld daalt, zijn de bedrijven minder tot voorspellen in staat. Dit wijst erop dat men het omslaan van ontwikkelingen moeilijk voorspellen kan.

- De voorspelkwaliteit is omgekeerd evenredig met de tijd die tot de realisatie van de te voorspellen grootheid te gaan is.

- Het voorspellen van de omzet is veel gemakkelijker dan het voorspellen van de netto winst, zeker als we de procentuele voorspelfouten beschouwen (zie v.d. Gaag e.a. (1979)).

De moeilijkheid van de voorspelbaarheid van de winst blijkt als we de winst 
als verschil tussen omzet en kosten zien. Dan volgt de variantie (var) van de winst: $\operatorname{var}($ winst $)=\operatorname{var}($ omzet $)-2 \operatorname{cov}$ (omzet, kosten) $+\operatorname{var}$ (kosten). Als het grootste deel van de kosten uit vaste kosten bestaat, dan vallen var(kosten) en de covariantie (cov) van omzet en kosten weg. Het resultaat is dan dat de varianties van omzet en winst gelijk zijn, terwijl de gemiddelden zeer veel verschillen; dit resulteert dan ook in een hogere variatiecoëfficiënt voor de winst dan voor de omzet en als gevolg in grotere procentuele voorspelfouten.

Tenslotte moet worden opgemerkt, dat de conclusies uit prognose-onderzoek niet zonder meer gegeneraliseerd kunnen worden. Veelal is de steekproef niet representatief of er is sprake geweest van specifieke omstandigheden. De prognose-onderzoeken, die in Amerika uitgevoerd zijn, zijn gebaseerd op gepubliceerde gegevens. Het is echter mogelijk dat alleen die ondernemingen prognoses publiceren, die van mening zijn, dat ze betrekkelijk nauwkeurig kunnen voorspellen. Analoge argumenten zijn van toepassing op voorspellingen van financiële analisten.

\section{Mogelijkheden en beperkingen van de gebruikte voorspelmethoden}

Het toepassen van voorspeltechnieken teneinde prognostische schattingen te verkrijgen is niet triviaal. Veelal is de hoeveelheid historische informatie beperkt en kenmerkt ze zich door structurele breuken. De reekslengte doet vaak besluiten geen ARIMA model aan de data aan te passen. Selecteren we een ARIMA model, dan mogen er geen structurele breuken in de reeks aanwezig zijn. Het analyseren van de reeks op zich is niet altijd afdoende om de aanwezigheid van een structurele breuk op te sporen. Een aantal structurele breuken kan men echter uit het financiële jaarverslag halen. Voorbeelden hiervan zijn: fusie, afstoting van grote productie-eenheden, inflatie, plotselinge ontwikkelingen op de markt, internationale crisis en niet ingecalculeerde conjuncturele ontwikkelingen.

In plaats van een ARIMA model kunnen we ook een causaal model opstellen. Het is mogelijk dat een structurele breuk voor een causaal model niet fataal is, terwijl dit voor een ARIMA model wel het geval is. Bijvoorbeeld een verandering in een beleidsvariabele kan door een causaal model geïncorporeerd worden, terwijl dit de aanpassing van een ARIMA model kan bemoeilijken of zelfs onmogelijk kan maken.

Onder de voorspelmodellen kan men ook de modellen rekenen die de te verklaren variabele zien als functie van de tijd. Deze vallen onder de deterministische modellen. Daar deze modellen niet met zekerheid verklaren voegt men een stochast aan deze functie toe (zie tabel 1) en probeert men met betrekking tot een zeker criterium een optimale aanpassing van de functie aan de reeks van waarnemingen te verkrijgen. Trendextrapolaties blijken veelal redelijke voorspellingen op te leveren, echter a priori is niet duidelijk onder welke voorwaarden dit model ook voor toekomstige perioden van toepassing zal zijn. Bijvoorbeeld het vervangen van een trendmatig 
verlopende exogene variabele door een trendterm is er de oorzaak van dat in het geval van het omslaan van de trendmatige ontwikkeling van de exogene variabele het trendmodel niet meer van toepassing is.

Veelal blijkt het niet mogelijk om een ARIMA model te bepalen, omdat de reeks van waarnemingen te kort is of onderhevig is aan structurele breuken. Toch is men soms in staat een kwalitatieve uitspraak te doen, zoals 'Ook dit jaar zal de omzetstijging ongeveer gelijk zijn aan die van vorige jaren' of 'We verwachten dit jaar een gelijke groei te realiseren als in het voorafgaande jaar'. In het volgende onderdeel zullen wij proberen om voor een drietal ondernemingen een meer kwantitatieve inhoud te geven aan deze kwalitatieve uitspraken. We beschouwen een aantal simpele lineaire modellen en bepalen de voorspelling als de verwachting van het model voorwaardelijk op de informatie in de waarnemingen van de te voorspellen grootheid.

\section{Het genereren van voorspellingen: enkele voorbeelden}

In dit onderdeel zullen wij enkele voorbeelden geven van modellen voor omzet en winst. Bij de keuze van de reeksen hebben wij ons laten leiden door het illustratieve karakter van de modellen, die op deze reeksen toegepast kunnen worden.

\subsection{Omzet en winst van AHOLD}

Wij beschikken over 31 waarnemingen uit de jaren 1948 tot en met 1978 . De gegevens zijn ontleend aan de jaarverslagen van AHOLD. Het blijkt (zie figuur 1) dat de reeksen voor de omzet en de netto winst niet stationair zijn over de gebruikte periode. Het bedrijf maakt over de eerder vermelde periode een strikt monotone groei van de omzet door, die veroorzaakt wordt door prijsstijgingen en volumetoename. We gaan in de eerste plaats na of we het verloop van de omzet en winst m.b.v. een tijdreeksmodel kunnen modelleren. Transformeren we de reeksen in logaritmen (ln) en nemen we dan eerste verschillen, dan blijken de verkregen reeksen stationair te zijn. Geen enkele autocorrelatie en partiële autocorrelatie (zie figuur 3 voor de omzet) voor omzet en winst is significant verschillend van nul bij een significantie-niveau van $5 \%$ (de gestippelde lijn in figuur 3 ). Hieruit concluderen we dat er geen aanleiding is een ARIMA proces te veronderstellen met $p$ en $q$ verschillend van nul. De normaliteit van een reeks kan onderzocht worden m.b.v. de Kolmogorov-Smirnov toets. Bijvoorbeeld, voor de omzetreeks wordt de nulhypothese - de realisaties komen uit een normale verdeling - niet verworpen. Voor de toepassing van deze toets is echter onafhankelijkheid van de getransformeerde waarnemingen vereist, een veronderstelling, die niet tegenstrijdig is met de niet significante autocorrelaties en partiële autocorrelaties. Is de reeks stationair zonder dat de waarnemingen van elkaar onafhankelijk zijn, dan kan de normaliteitshypothese m.b.v. de toets van Lomnicki (1961) onderzocht worden. Deze toets is echter van toepassing in grote steekproeven.

Op grond van de conclusies uit de analyse van de autocorrelatie functies modelleren we de getransformeerde reeksen als onafhankelijke normaal 

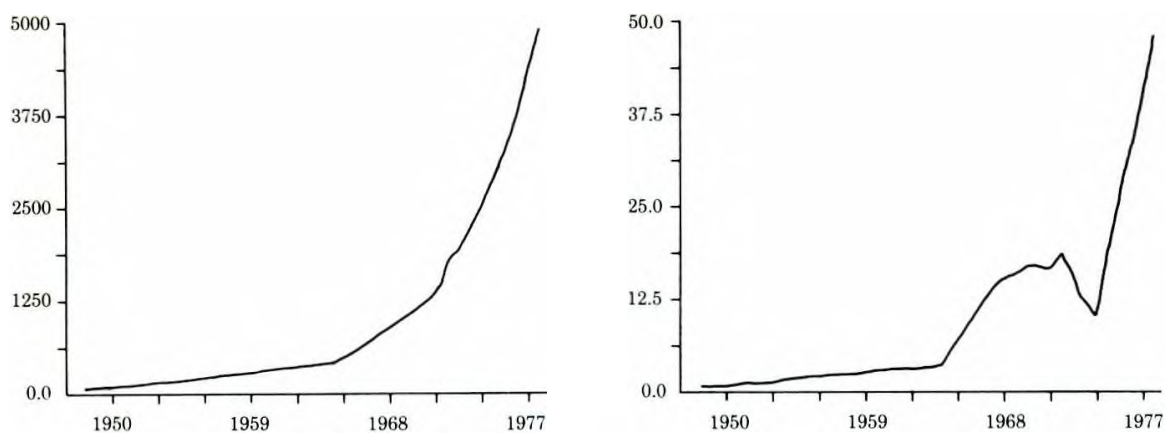

Fig. 1 Omzet en netto winst van AHOLD (in miljoenen guldens)

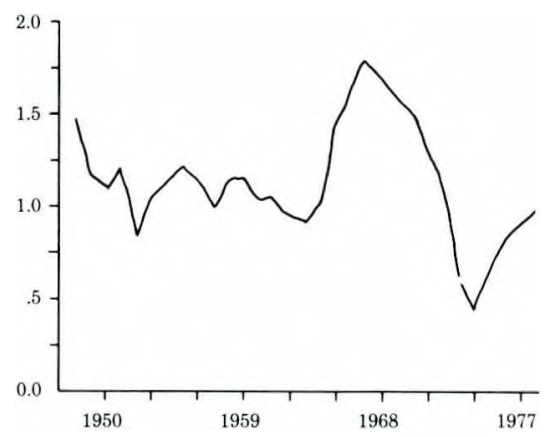

Fig. 2 Netto winst in procenten van de omzet, AHOLD
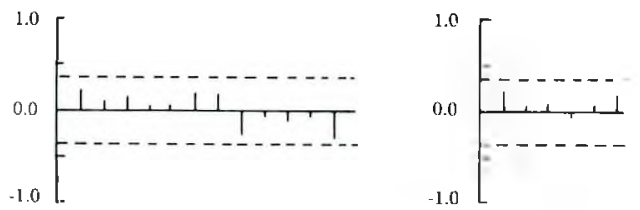

Fig. 3 Autocorrelaties en partiële autocorrelaties van de omzet van AHOLD
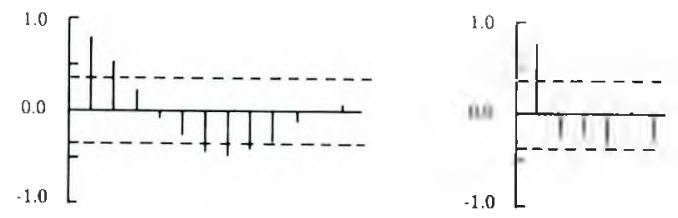

Fig. 4 Autocorrelaties en partiële autocorrelaties van de netto winst in procenten van de omzet, AHOLD 
Tabel 2 Modellen voor Omzet en Winst

\begin{tabular}{|c|c|c|c|c|c|c|}
\hline $\begin{array}{l}\text { Reeks } \underline{y}_{\mathrm{t}} \\
\text { (in miljoenen } \\
\text { guldens) }\end{array}$ & Periode & & Model* & $\begin{array}{l}\text { Voorspelling voor } \\
\underline{x}_{t} \text {, één en twee } \\
\text { perioden vooruit }\end{array}$ & Voorspellingsinterval voor $\mathbf{L}_{1}$ & $\begin{array}{l}\text { Realisatie } \\
y_{t}\end{array}$ \\
\hline $\begin{array}{l}\text { omzet (0.) } \\
\text { AHOLD }\end{array}$ & $1948-78$ & $\begin{array}{c}\Delta \ln y_{\mathrm{t}} \\
\hat{\theta}^{2}\end{array}$ & $\begin{array}{l}=.1482+\varepsilon_{\mathrm{t}} \\
(.0115) \\
=.00395\end{array}$ & $\begin{array}{l}\text { 1979: } 5730 \\
\text { 1980: } 6645\end{array}$ & $\begin{array}{l}50 \%: 5490 ; 5980 \\
95 \%: 5030 ; 6510 \\
50 \% ; 6240 ; 7070 \\
95 \%: 5510 ; 8016\end{array}$ & $\begin{array}{l}5324.53 \\
5822 .\end{array}$ \\
\hline $\begin{array}{l}\text { omzet } \\
\text { AHOLD }\end{array}$ & $1965-78$ & $\begin{array}{c}\Delta \ln \mathrm{y}_{\mathrm{l}} \\
\theta_{1}^{2}\end{array}$ & $\begin{array}{l}=.1832+\hat{\varepsilon}_{n} \\
(.039) \\
=.0022\end{array}$ & $\begin{array}{l}\text { 1979: } 5930 \\
\text { 1980: } 7122\end{array}$ & $\begin{array}{l}50 \%: 5750 ; 6130 \\
95 \%: 5390 ; 6530 \\
50 \%: 6780 ; 7490 \\
95 \%: 6110 ; 8310\end{array}$ & $\begin{array}{l}5324.53 \\
5822 .\end{array}$ \\
\hline $\begin{array}{l}\text { netto winst } \\
\text { (n.w.) AHOLD }\end{array}$ & $1948-78$ & $\begin{array}{c}\Delta \ln y_{1} \\
\partial^{2}\end{array}$ & $\begin{array}{l}=.1342+\varepsilon_{1} \\
(.12) \\
=.0433\end{array}$ & $\begin{array}{l}\text { 1979: } 55.60 \\
\text { 1980: } 63.59\end{array}$ & $\begin{array}{l}50 \%: 48.20 ; \quad 64.10 \\
95 \%: 36.30 ; 81.51 \\
50 \%: 51.60 ; 78.20 \\
95 \%: 34.10 ; 118.30 \\
\end{array}$ & $\begin{array}{l}50.202 \\
51.863\end{array}$ \\
\hline $\begin{array}{l}\text { netto winst } \\
\text { AHOLD }\end{array}$ & $1948-78$ & $\begin{array}{l}\mathrm{z}_{\mathrm{t}} \\
\mathrm{z}_{\mathrm{t}} \\
\hat{\sigma}_{\mathrm{t}}^{2}\end{array}$ & $\begin{aligned}= & 1.156 \mathrm{z}_{\mathrm{t}-1}-.407 \mathrm{z}_{\mathrm{t}-2} \\
& (.1632)(.1645) \\
+ & .2918+\hat{\varepsilon}_{\mathrm{t}} \\
& (.1208) \\
= & \frac{\text { n.w. }}{\mathrm{O} .} \times 100 \\
= & .0313\end{aligned}$ & $\begin{array}{l}\text { 1979: } 63.10 \\
\text { 1980: } 79.80\end{array}$ & $\begin{array}{l}\min 47.5 \%: 41.20 ; 86.50 \\
\min 90.3 \%: 38.60 ; 92.10 \\
\min 47.5 \%: 60.30 ; 93.70 \\
\min 90.3 \%: 56.80 ; 97.09\end{array}$ & $\begin{array}{l}50.202 \\
51.863\end{array}$ \\
\hline $\begin{array}{l}\text { netto winst } \\
\text { KWATTA }\end{array}$ & $1976-78$ & $\begin{array}{l}y_{1} \\
\mu\end{array}$ & $\begin{array}{l}=\mu+\hat{\varepsilon}_{t} \\
=\frac{1}{2} y_{t-1}+\frac{1}{4} y_{t-2}+\frac{1}{4} y_{t-3}\end{array}$ & $\begin{array}{l}1979: .273 \\
1980: .311\end{array}$ & $\begin{array}{lrr}50 \% ; & .2654 ; & .2806 \\
95 \%: & .1771 ; & .3689 \\
50 \%: & .2155 ; & .4066 \\
95 \%: & -.9030 ; & 1.5250 \\
\end{array}$ & $\begin{array}{l}.435 \\
.401\end{array}$ \\
\hline $\begin{array}{l}\text { omzet } \\
\text { NEDAP }\end{array}$ & 1965-78 & $\ln y_{1}$ & $\begin{aligned}= & 1.896+.826 \ln 0_{r_{w i}} \\
& (.342) \quad(.038) \\
+ & \mathrm{D}+\varepsilon_{\mathrm{t}}, \sigma_{t}^{2}=.0816\end{aligned}$ & $\begin{array}{l}\text { 1979: } 25.203 \\
\text { 1980: } 28.171\end{array}$ & $\begin{array}{l}50 \%: 20.768 ; 30.540 \\
95 \%: 14.388 ; 44.086 \\
50 \% ; 22.726 ; 34.922 \\
95 \% ; 15.098 ; 52.564 \\
\end{array}$ & $\begin{array}{l}26.14 \\
26.36\end{array}$ \\
\hline $\begin{array}{l}\text { winst voor } \\
\text { belasting } \\
\text { NEDAP }\end{array}$ & $1965-78$ & $y_{1}$ & $\begin{aligned}= & .187 \mathrm{O}_{\mathrm{t}}-3.16 \mathrm{~A}_{\mathrm{t}} \\
& (.0152)(1.159) \\
+ & 591.08+\hat{\varepsilon}_{\mathrm{t}} \\
(277.63) & \\
\hat{\phi}_{1}^{\mathrm{c}} & =.1871 \\
& \mathrm{O}_{\mathrm{t}}=\text { omzet } \\
& \mathrm{A}_{\mathrm{t}}=\text { afschrijvingen }\end{aligned}$ & $\begin{array}{l}1979:-.150 \\
1980:-.916\end{array}$ & $\begin{array}{rrr}50 \% ; & -.650 ; & .350 \\
95 \% ; & -1.603 ; & 1.303 \\
50 \% ; & -1.417 ; & -.416 \\
95 \% ; & -2.369 ; & .537\end{array}$ & $\begin{array}{r}.910 \\
-.626 \\
\end{array}$ \\
\hline
\end{tabular}

* Standaard-fouten zijn tussen haakjes vermeld. 
verdeelde stochasten met gemiddelde $\mu$ en variantie $\sigma^{2}$. De schattingsresultaten worden in tabel 2 vermeld. Puntvoorspellingen voor omzet en winst zijn verkregen door eerst voorspellingen voor ln (omzet) en ln (winst) te genereren en vervolgens de antilog-transformatie toe te passen. Op deze wijze worden mediaan-zuivere voorspellingen van omzet en winst verkregen. Het is niet mogelijk om zuivere voorspellingen te bepalen, omdat de parameters van het log-lineaire model niet bekend zijn en geschat moeten worden (zie ook Kodde (1981)).

Een $100 \gamma \%$ voorspellingsinterval voor ln (omzet in 1979) wordt bepaald door $\ln$ (omzet in 1978) $+\bar{y} \pm \frac{1+1+\gamma}{s}$ (29) $\mathrm{S} \sqrt{1+\frac{1}{30}}$, waarbij $\bar{y}$ en $\mathrm{S}^{2}$ zuivere schatters voor $\mu$ en $\sigma^{2}$ zijn, en $t_{\pi}(n)$ het punt is, waar de cumulatieve student $t$ verdeling met $n$ vrijheidsgraden de waarde $\pi$ aanneemt. Voorspellingen en voorspellingsintervallen voor de jaren 1979 en 1980 worden in tabel 2 gegeven. Opgemerkt moet worden, dat de waarnemingen voor deze jaren beschikbaar kwamen nadat de modellen geselecteerd werden. De realisaties liggen binnen het $95 \%$ voorspellingsinterval (zie tabel 2).

Als wij naar figuur 1 kijken, dan zien wij omstreeks de helft van de periode een exponentieel verloop van de omzet, terwijl het begin van de reeks zich meer door een lineair verloop laat typeren. We toetsen op de aanwezigheid

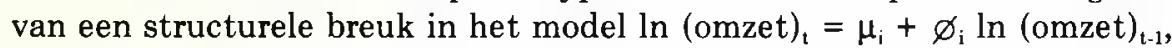
met $\mathrm{i}=1$ voor $\mathrm{t}=2, \ldots 17$, en $\mathrm{i}=2$ voor $\mathrm{t}=18, \ldots 31$. De nulhypothese, waar we voor de gehele periode eenzelfde verband veronderstellen, luidt nu $H_{o}: \mu_{1}=\mu_{2}$ en $\varnothing_{1}=\varnothing_{2}$. De logaritme van het quotiënt van de aannemelijkheidsfuncties, $\ln \lambda(2 \ln \lambda$ heeft een chi-kwadraat verdeling met 2 vrijheidsgraden), bedraagt 12.72 , zodat wij de hypothese, er is geen structurele verandering, verwerpen. Het model, dat geschat wordt uit de laatste 14 waarnemingen van de omzet, wordt vermeld in tabel 2. De nieuw gevonden voorspellingsintervallen zijn korter, doordat de geschatte normale verdeling een lagere variantie heeft. $\mathrm{Bij}$ het berekenen van voorspellingen wordt nu meer waarde gehecht aan de groei in de latere jaren, waardoor deze groei ook voor de jaren 1979 en 1980 doorgetrokken wordt.

De voorspellingsintervallen voor de netto winst zijn relatief groot t.o.v. die voor de omzet, hetgeen wij al eerder opgemerkt hebben. Wij zullen proberen tot kleinere voorspellingsintervallen te komen en gaan daarom na of er reeksen zijn, waarvan het product de netto winst vormt. Deze aanpak wordt o.a. beschreven in Brown (1962). De reeksen, die wij zoeken, moeten echter eenvoudiger te voorspellen zijn dan de netto winst reeks. Reeksen, die naar verwachting aan deze voorwaarden voldoen, zijn omzet en netto winst als percentage van de omzet. Het percentage netto winst van de omzet vertoont een stationair karakter, mogelijk in de latere perioden een niet-stationariteit in de variantie (zie figuur 2). Van deze complicerende factor abstraheren wij echter.

De geschatte partiële autocorrelatie functie in figuur 4 is afgekapt na één 
periode, hetgeen wijst op een eerste orde autoregressief model. De autocorrelatie functie echter vertoont veel overeenkomst met de theoretische autocorrelatie functie van een tweede orde autoregressief proces zoals getekend in Box en Jenkins (1970, blz. 59). Op grond van deze analyse is dan ook geen eenduidige specificatie te verkrijgen. Daarom werden meerdere geneste alternatieve modellen bekeken en werd m.b.v. een aannemelijkheidsquotiënt-toets een selectie gemaakt.

De conclusie luidt dat men er niet bij gebaat is om een eenvoudiger alternatief model te hanteren. Het combineren van de voorspellingen van omzet en van netto winst in procenten van de omzet verkregen m.b.v. een tweede orde autoregressief proces geeft een (mediaan-zuivere) puntvoorspelling voor de winst (zie tabel 2). Bij het combineren van de voorspellingen zijn we er vanuit gegaan dat de correlatie tussen de twee reeksen nul is. Een voorspellingsinterval voor het product van twee onafhankelijke stochasten kunnen we berekenen door de verdeling van het product te bepalen, hetgeen soms veel rekenwerk vergt. We geven een ondergrens voor de betrouwbaarheid van het product, door uit te gaan van de enkele voorspellingsintervallen.

Indien $\mathrm{P}\left(\mathrm{t}_{1} \leqslant \underline{\mathrm{x}} \leqslant \mathrm{t}_{2}\right)=1-\alpha_{1}$ en $\mathrm{P}\left(\mathrm{t}_{3} \leqslant \underline{\mathrm{y}} \leqslant \mathrm{t}_{4}\right)=1-\alpha_{2}$, dan volgt als ondergrens voor de betrouwbaarheid van het product xy indien $t_{1}, t_{3} \geqslant 0$

$\mathrm{P}\left(\mathrm{t}_{1} \mathrm{t}_{2} \leqslant \underline{\mathrm{x}} \underline{\mathrm{y}} \leqslant \mathrm{t}_{3} \mathrm{t}_{4}\right) \geqslant\left(1-\alpha_{1}\right)\left(1-\alpha_{2}\right)$. De variabele $\underline{\mathrm{x}}$ kan bijv. als de nog onbekende omzetrealisatie beschouwd worden en $y$ staat voor de onbekende netto winst als percentage van de omzetrealisatie, waardoor $\underline{x y}$ de onbekende winstrealisatie aangeeft. In tabel 2 wordt de ondergrens van het voorspellingsinterval voor de netto winst van AHOLD vermeld. Uit het gebruik van verschillende modellen blijkt dat het toepassen van meer geavanceerde technieken vrijwel dezelfde voorspellingen oplevert, hetgeen de door andere auteurs gevonden resultaten bevestigt.

\subsection{Netto winst van Kwatta}

Omstreeks het jaar 1976 is Kwatta, na een lange reeks jaren verliesgevend te hebben geproduceerd, een houdstermaatschappij geworden. Dit impliceert dat er in 1976 een structurele breuk heeft plaatsgevonden, waarvan de effecten nog enige jaren door zullen werken. Doordat Kwatta de productie bijna volledig heeft afgestoten, is het niet zinvol de omzet te voorspellen. We beperken ons alleen tot het voorspellen van de netto winst.

Voor het voorspellen hebben we de volgende veronderstellingen gemaakt:

- de gerealiseerde winsten $y_{t}$ zijn te benaderen door een $N\left(\mu, \sigma^{2}\right)$ verdeling, waarbij we onafhankelijkheid tussen de winsten veronderstellen;

- voor volgende perioden is dezelfde verdeling van toepassing;

- de invloed van de structurele verandering in 1976 is zo groot, dat we recente jaren meer gewicht geven. 
De reeks bestaat uit drie waarnemingen n.l. $(49,337,353)=W^{\prime}$ (in duizenden guldens). We kiezen de vector van gewichten $a^{\prime}=\left(\frac{1}{4}, \frac{1}{4}, \frac{1}{2}\right)$. Hierbij moeten we een idempotente matrix $Q$ vinden, waarvoor geldt $\mathrm{Qa}=0$ :

$$
\mathrm{Q}=\left[\begin{array}{rrr}
\frac{1}{2} & -\frac{1}{2} & 0 \\
-\frac{1}{2} & \frac{1}{2} & 0 \\
0 & 0 & 0
\end{array}\right]
$$

Dan heeft de grootheid $\frac{\underline{\mathrm{Y}}_{79}-\underline{\underline{W}}^{\prime} \mathrm{a}}{V_{\underline{W^{\prime}}} \mathrm{QW}} \frac{V_{8}}{V_{11}}$ een student $t$ verdeling met één vrijheidsgraad. Een puntvoorspelling en voorspellingsintervallen zijn nu makkelijk te berekenen (zie tabel 2) zonder dat de variantie $\sigma^{2}$ geschat moet worden. Op dezelfde wijze worden voorspelling en voorspellingsinterval voor 1980 berekend.

\subsection{Omzet en winst van NEDAP}

In tegenstelling tot AHOLD is NEDAP conjunctuurgevoelig. De bedrijfsvoering is direct afhankelijk van investeringen van andere bedrijven. Er zijn gegevens beschikbaar voor de periode van $1965 \mathrm{t} / \mathrm{m}$ 1978. NEDAP heeft ook de orderportefeuille aan het eind van het jaar in het jaarverslag opgenomen.

In figuur 5 is het verloop van de omzet en de orderportefeuille over de bovengenoemde periode aangegeven. De reeksen tonen een regelmatig verloop tot 1974 of 1975 , waarna de oliecrisis van invloed is op de bedrijvigheid. Deze breuk is vooral goed zichtbaar in de omzetreeks voor het jaar 1975 en in 1976 voor de orderportefeuille waarbij verwachtingen t.a.v. de economische ontwikkeling een grote rol hebben gespeeld. Daar de oliecrisis niet expliciet gemodelleerd wordt, zal bij de verklaring van de omzet een dummy variabele voor het jaar 1975 opgenomen worden. Deze variabele zal aangegeven worden met een D.

Om de omzet van NEDAP te voorspellen hebben wij meerdere modellen onderzocht. De puntvoorspellingen van deze modellen verschillen niet veel van elkaar. Daarom zullen wij ons hier beperken tot een korte weergave van de specificatie van één model (voor de overige modellen verwijzen we naar Kodde (1981)). We veronderstellen dat de orders binnen een jaar afgewerkt worden en dat de orderportefeuille aan het begin van het jaar proportioneel is met de orders, die in het jaar binnenkomen en ook binnen het jaar afgewerkt worden. Als model krijgen we dan

$$
\mathrm{O}_{\mathrm{t}}=\left(1+\mathrm{g}_{\mathrm{t}}\right) \mathrm{O}_{\mathrm{r}_{\mathrm{t}-1}},
$$

waarbij $g_{t}$ een proportionaliteitsfactor in jaar $t$ is, $O_{t}$ is de omzet en $O_{r}$ is de orderportefeuille in het jaar $t$. We veronderstellen, dat $g_{t}=g$ constant is en schatten het algemenere model $\underline{O}_{t}=(1+g) O_{r_{i-1}}^{\alpha} e^{D+\varepsilon_{t .}}$ De schattingsresultaten worden in tabel 2 vermeld. De parameter $\alpha$ is significant verschillend van 1 . Dit is reden het model met $\alpha=1$ te verwerpen en de voorspellingen m.b.v. het algemenere model te genereren (zie tabel 2). 


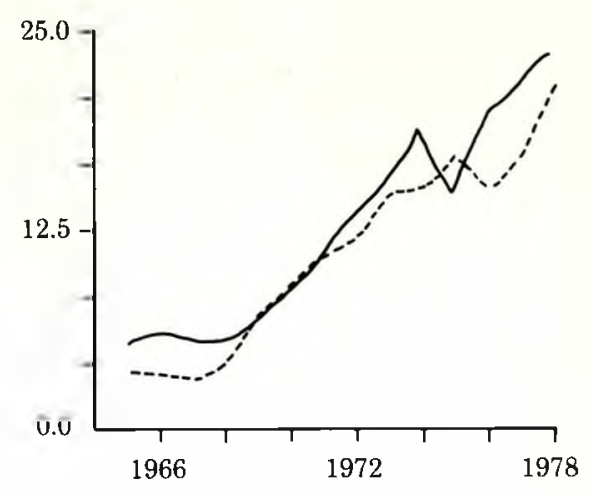

Fig. 5 NEDAP: Omzet

Orderportefeuille: _ _ _

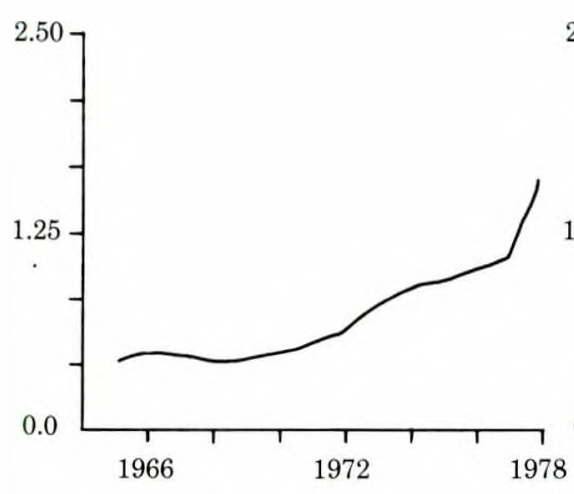

Afschrijuingen

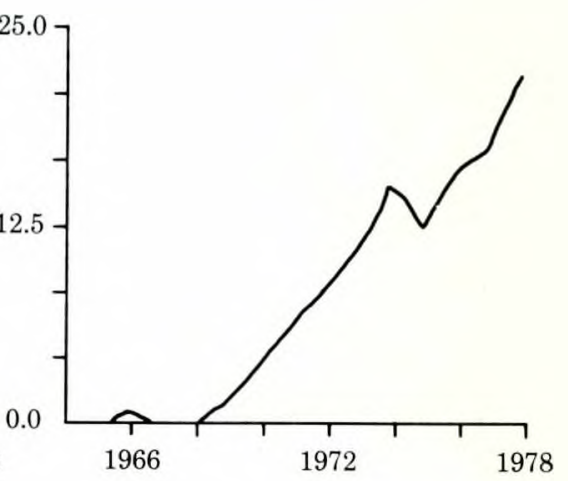

Totale kosten

(in miljoenen guldens)

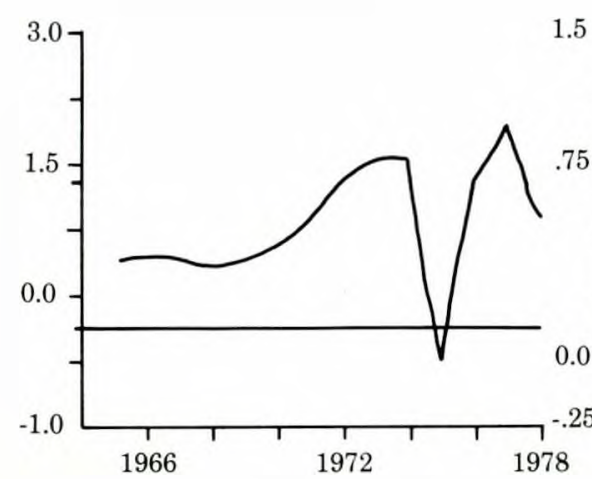

Winst voor belasting

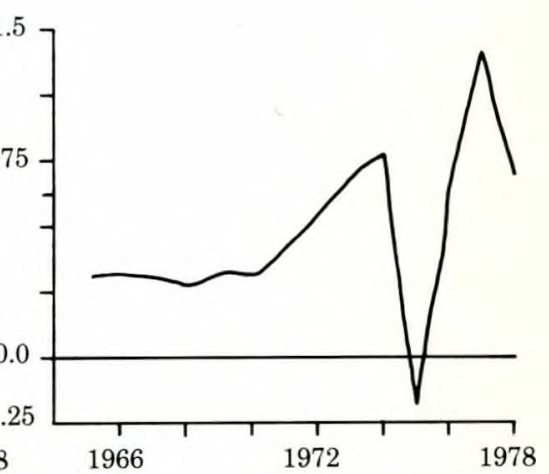

Netto winst 
We bepalen een voorspelling voor de netto winst van NEDAP door eerst een model te specificeren voor de winst vóór belasting, d.w.z. het verschil tussen omzet en kosten. De kosten vatten wij op als zijnde opgebouwd uit vaste en variabele kosten. We veronderstellen dat de variabele kosten een vaste verhouding vertonen met de prijs van de producten. Dit impliceert de relatie $C V_{t}=\alpha_{1} \mathrm{O}_{t}$, waarbij $\mathrm{CV}_{\mathrm{t}}$ de variabele kosten zijn en $\mathrm{O}_{\mathrm{t}}$ de omzet voorstelt. Voor de vaste kosten veronderstellen we de volgende vergelijking $C_{t}=\alpha_{2} A_{t}+\alpha_{3}$, waarbij $C_{t}$ de vaste kosten en $A_{t}$ de afschrijvingen zijn. De overwegingen om tot de vorm van deze vergelijking te komen worden gevonden in Pakkala (1979). Voor de winst, $W_{t}$, geldt nu de relatie

$$
\mathrm{W}_{\mathrm{t}}=\left(1-\alpha_{1}\right) \mathrm{O}_{\mathrm{t}}-\alpha_{2} \mathrm{~A}_{\mathrm{t}}-\alpha_{3} \text {. }
$$

De schattingsresultaten voor deze vergelijking worden in tabel 2 gegeven. Willen we nu de winst voorspellen, dan moeten wij eerst informatie over de afschrijvingen voor het betreffende jaar hebben. We veronderstellen hiervoor dat de verandering van $A_{t}$ constant is, $\Delta A_{t}=\Delta A_{t \cdot 1}$. Vullen we de voorspellingen voor omzet en afschrijvingen in de geschatte winstvergelijking in, dan krijgen we een puntvoorspelling voor de winst vóór belasting, waarop men een vennootschapsbelastingtarief van $47 \%$ moet toepassen om tot een voorspelling van de netto winst te komen.

\section{Enkele conclusies}

In het vorige hoofdstuk hebben we voor meerdere bedrijven voorspellingen voor omzet en netto winst gegenereerd, zoals deze ondernemingen de grootheden in het jaarverslag publiceren. Hierbij bleek, dat voorspellingen gegenereerd volgens geavanceerde methoden soms niet veel afwijken van voorspellingen gegenereerd m.b.v. naïeve modellen. Onder bepaalde voorwaarden, kunnen de ARIMA modellen, zoals beschreven in hoofdstuk 2, beschouwd worden als een oplossing van een lineair simultaan model, waarin o.a. omzet en winst van een bepaalde onderneming verklaard worden. Voor een niet-lineair simultaan model laat Wallis (1981) zien dat het gebruik van een enkelvoudig ARIMA model soms een kleinere gemiddelde kwadratische voorspelfout impliceert dan het complete niet-lineaire model. Verder merken wij op, dat het voorspellen m.b.v. causale modellen (zie NEDAP) ook niet vrij is van ad hoc veronderstellingen. Naast de ad hoc elementen, die moeilijk helemaal te voorkomen zijn, is het voor degene, die voorspellen wil met een causaal model van belang, dat de waarden van de verklarende variabelen bekend zijn of dat hij in staat is een model voor deze variabelen te specificeren. Een voorbeeld hiervan zijn de afschrijvingen van NEDAP, die onbekend waren en waarvoor we een ARIMA $(0,2,0)$ model gepostuleerd hebben.

De vele onzekerheden omtrent de specificatie, de korte reeksen en de aanwezigheid van structurele breuken doen ons twijfelen of het voorspellen met meer geavanceerde econometrische modellen, waarvoor mogelijk een kleiner voorspellingsinterval verkregen kan worden, opweegt tegen de extra kosten, die het specificeren van deze modellen met zich meebrengt. Deze 
conclusie kan echter alleen voor dit onderzoek getrokken worden en moet bij ander onderzoek steeds weer geverifieerd worden.

\section{Geraadpleegde literatuur}

Ball, R., and R. Watts (1972): 'Some Time Series Properties of Accounting Income', Journal of Finance, 27, 663-682.

Basi, B. A., Carey, J. J., and R. D. Twark (1976): 'A Comparison of the Accuracy of Corporate and Security Analysts' Forecasts of Earnings', The Accounting Review, 51, 244-254.

Box, G. E. P., and G. M. Jenkins (1970): Time Series Analysis, Forecasting and Control, Holden-Day, Inc.

Brown, R. G. (1962): Smoothing, Forecasting and Prediction of Discrete Time Series, PrenticeHall, Inc.

Elton, E. J., and M. J. Gruber (1972): 'Earnings Estimates and the Accuracy of Expectational Data', Management Science, 18, 409-424.

Foster, G. (1977): 'Quarterly Accounting Data: Time Series Properties and Predictive-Ability Results', The Accounting Review, 12, 1-20.

Gaag, J. J. v. d., en J. E. Matthée (1979): 'De wenselijkheid van prognoses in het gepubliceerde jaarverslag', Erasmus Universiteit Rotterdam, Rapport 7927/ACO.

Green, D., and J. Segall 1967): 'The Predictive Power of First-Quarter Earnings Reports', The Journal of Business, 40, 44-55.

Hopwood, W. S., and P. Newbold (1980): 'Time Series Analysis in Accounting: A Survey and Analysis of Recent Issues', Journal of Time Series Analysis, 1, 135-144.

Kodde, D. A. (1981): 'Het genereren en evalueren van voorspellingen van omzet en netto winst: een toegepast kwantitatieve benadering', Economische Faculteit, V.U., Amsterdam, RM 1981-7.

Lomnicki, Z. A. (1961): 'Tests for Departure from Normality in the Case of Linear Stochastic Processes', Metrika, 4, 37-62.

Lorek, K. S., McDonald, C. L., and D. H. Patz (1976): 'A Comparative Examination of Management Forecasts and Box-Jenkins Forecasts of Earnings', The Accounting Review, 51, 321-330.

Nelson, C. R. (1973): Applied Time Series Analysis for Managerial Forecasting, Holden-Day, Inc.

Pakkala, A. L. (1979): 'Fixed Costs Impact Earnings', Financial-Analysts Journal, 46-48.

Ruland, W. (1978): 'The Accuracy of Forecasts by Management and by Financial Analysts', The Accounting Revieu, 53, 439-447.

Wallis, K. F. (1981): 'Notes on Forecast Evaluation in Nonlinear Models', Paper presented at the Econometric Society Meeting, Amsterdam.

Watts, R. L., and R. W. Leftwich (1977): 'The Time Series of Annual Accounting Earnings', Journal of Accounting Research, 15, 253-271.

Winkel, E. G. F. van, (1979): ARIMA-Processen, De betekenis van univariate methoden voor de econometrie, Academisch Proefschrift, Vrije Universiteit, Amsterdam. 